\title{
Manufacturing Transformational Change Through Asset Orchestration
}

\author{
R. Abdullah ${ }^{1}$, R. H. Weston ${ }^{2}$, H.O. Mansoor ${ }^{3}$, P.M. Jackson ${ }^{4}$, S. King ${ }^{4}$ \\ ${ }^{1}$ Faculty of Mechanical and Manufacturing Engineering Technology, Universiti Teknikal \\ Malaysia Melaka, Malaysia \\ ${ }^{2}$ Manufacturing Modelling Ltd, Loughborough, United Kingdom \\ ${ }^{3}$ College of Administration and Economics, University of Al Fallujah, Iraq \\ ${ }^{4}$ University of Leicester, United Kingdom \\ rohana_abdullah@utem.edu.my
}

\begin{abstract}
By documenting a case of transformational change in a MultiNational Company this paper brings together conceptual thinking from management and systems engineering schools to propose a new systematic approach to the application of emergent asset orchestration theory. When so doing the paper illustrates how collective decision making amongst multiple management teams, responsible for large scale organisational change, can be systematically integrated and enabled at multiple-levels of abstraction.
\end{abstract}

Keywords: Asset Orchestration, Transformational Change, Dynamic Systems Modelling, Resource Based View

\subsection{Introduction}

Firms must be flexible to allow them to adapt strategically and respond rapidly and effectively to market change [1]. When so doing, typically they must adjust their operational processes to manage inherent complexities within the many systems they deploy [2].

Literature from strategic management schools reports upon the so called 'resource based view' (RBV) of firms [3]. Much of this literature explains that strategy realisation should focus on matching co-specialized resources and combinative capabilities to existing and new opportunities in external markets. Barney [4] states that for any firm to sustain a competitive advantage it will require rare, valuable, inimitable and non-substitutable resources. Yet the RBV of firms has been criticised as it does not on its own adequately explain how firms compete and maintain competitive advantage. Adner and Helfat [5a] posit that previous studies of firms' performances have neglected the relationship between management decisions and a firm's outcomes [6]. They also define the 'Dynamic Managerial Capabilities' (DMC) of any firm as being the capabilities with which managers incorporate, build and reconfigure organisation- 
al tools and competencies. Adner and Helfat [5b] further note that DMC is based on three prime attributes, namely (i) managerial human capital (ii) managerial social capital and (iii) managerial cognition capabilities.

Sirmon and Hitt [7] and Sirmon et al. [8a] describe a model of resource management to enable firms to cope with external change. This model is based on three concepts; (a) structuring of the company's asset portfolio (b) bundling and deploying capacity building resources and (c) leveraging the capabilities of companies.

Helfat et al. [9] and Teece [10] state that the key function of DMC is to realise asset orchestration (AO). They go on to define $\mathrm{AO}$ as comprising: managerial 'search and selection' typically followed by managerial 'configuration and coordination' of resources and capabilities. Sirmon et.al. [8b] also describe AO as a systematic method of of structuring, building and exploiting a company's assets to deliver value to its customers and competitive advantage to the company. They and other authors further emphasise that $\mathrm{AO}$ should be realised by managers to sustain competitive behaviours in firms, thereby highlighting the importance of a plethora of managerial abilities that sustain coordinated deployments of specialized and co-specialized assets.

Taylor and Helfat [11] consider characteristics of critically important roles played by top level managers in firms. Whereas, these authors posit that middle managers also have a critical role in linking upper and lower management levels; and when so doing they should organise the use of complementary assets resulting in their downstream configuration and/or reconfiguration. These authors also deliberate the integrating functions of middle managers to be a critical aspect of AO.

Chadwick et al. [12] explain that in order for top executive teams to achieve congruence between the firm's assets and changing market settings, typically decisions taken by top level managers must be supported by information, expertise and actions provided by middle-level managers. Teece [10b] argued that at times of significant change the redeployment of co-specialised assets invariably has a key role to play in firms. Whereas Taylor and Helfat (2009) add that having complementary assets is crucial but not generally enough alone to achieve new transitions. Taylor and Helfat [11b] further highlight the importance of dynamic capabilities possessed by middle management, placing particular emphasis of key middle management roles which act as connectors in aligning and linking the operationally distinctive organizational units that possess complementary assets.

According to Sirmon et al. [8c], the relationship between resource orchestration mechanisms and various levels of any asset hierarchy have yet to be clearly clarified. Nonetheless, Sirmon points to this as a literature gap which indicates that detailed explanation is needed to describe the typical relationships that exist between asset orchestration mechanisms and three levels of management commonly observed an organizational hierarchy. 
Based upon these reported findings, this paper then goes on to propose the use of an AO road map which is underpinned via simple multi-level of abstraction cognitive models in order to systemise the critical management decision-making aspects of AO within firms.

\subsection{Proposed Reference Model of Asset Orchestration}

To begin to address the observed gap in understanding about 'how AO mechanisms can be mapped onto common organising structures used by firms' this paper: (a) describes a new, visual reference model of asset orchestration; (b) gathers case study evidence about AO processes that have been used successfully to realise an actual scenarios of significant and transformational change in a world class firm.

The present authors have observed a gap in the current asset orchestration (AO) literature which will limit its systematic and practical application within different firms. Through thorough review of these literatures, the authors conceived a new reference framework for the implementation of $\mathrm{AO}$ processes.

This reference model is shown in Figure 1 and has been developed with functionality in mind to provide a ready-made visual guide on how companies 'resource based view' and the 'dynamic capabilities view' could be broadly and consistently applied in a variety of companies. The reference model is in a schematic form to demonstrate the multi-level mapping of key AO processes (of 'search', 'selection', 'configuration' and 'deployment') on a company's primary resources (especially its strategic, co-specialised and make or buy assets) so that responses can be made to a more flexible, sustained and competitive market changes. 


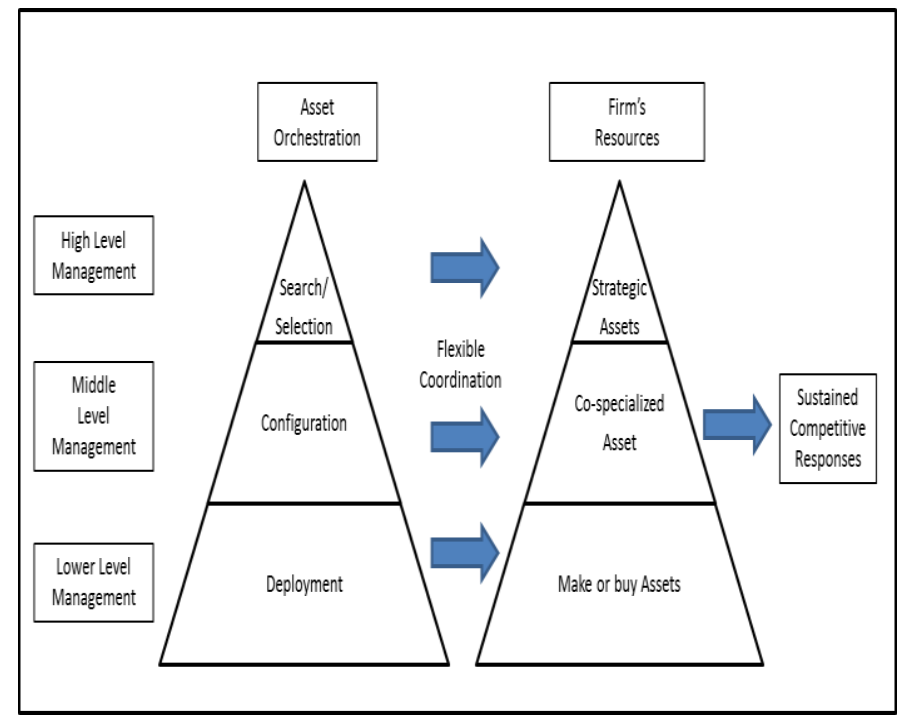

Fig. 1. Reference Model of Application of AO in a Firm

In Figure 1, reference is made to the 'depth' and 'breadth' found in the traditional decision making of a company. Here 'depth' refers to the different levels and roles of the organizational management within the firm, at which managerial decisions and actions occur, whilst 'breath' deals with the influence and the impact of any managerial decision on the firm.

Figure 1 also shows at each primary hierarchical tier, a clear description of a typical AO processes (thus, decision makings) that are carried out and also the common actions or outcomes that affect the key assets are listed. Nonetheless, AO processing across the hierarchical tiers will need to be consistent, requiring team effort amongst the managers. Importantly the range of detail (depth) and control (breadth) of the AO processing will vary depending on inherent characteristics of each $\mathrm{AO}$ process; the unique properties of each firm; and the particular environmental dynamics of the company.

Importantly, in order to maintain the success in this competive market environments, at least some degree $\mathrm{AO}$ analysis must continue leading to new searches, market selections, subsequent acquisitions of resources, configurations and installations over the life of the company and thus, over the life span of its current and prospective products and/or the existing and new services provided by the company.

In summary, although not taking into account the extremely complex nature of the companies, and their evolving markets environments and the requisite AO processes, Figure 1 provides a clear visual reference model of the present AO thinking. The following section dis- 
cussed the case study work performed and evidence of the practical application of this reference model.

\subsection{Case Study Results at GMS}

GMS is a leading and global producer of semiconductor components with prime end-customers in a range of industrial sectors covering electronics, automotive, and medical.

In this paper we retrospectively report on a substantial case of AO processing in GMS which followed the design and prototyping of a new electronic product. The AO processing described led to the distributed manufacture and global supply of that new product. Based upon the following reasoning, the magnitude and nature of the reported change led the present authors to characterise this as being a case of 'transformational change'.

A semi-structured interviews were held with the managers with individual responsibilities at each tier of the AO management and decision making within GMS. The interviews were partially in a free form but Figure 1 and Figure 2 were shown to the managers during the interviews to align their responses to recently published notions about AO. Figure 2 is an alternative version of Figure 1 and was developed by the present authors to work alongside Figure 1 as a 'visual interviewing' method to simplify, guide and assist to organise the questions and interview outcomes.

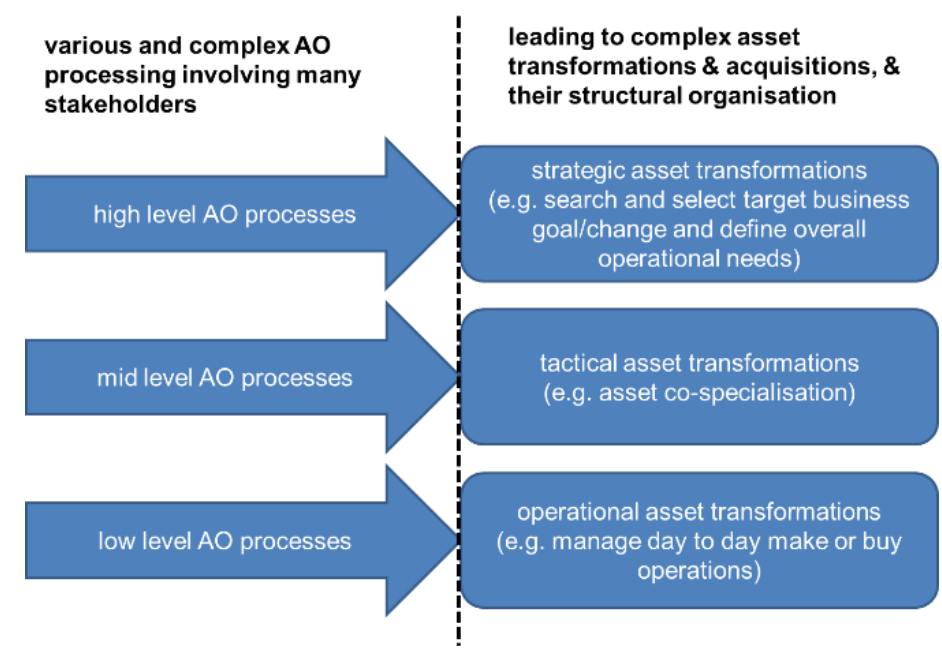

Fig. 2. Visual Aid Used to Semi-structure the Questioning of Managers 


\subsection{Discussions}

In our literature review, we found that real associations between asset orchestration mechanisms and different tiers of any asset hierarchy such as those proposed by McGee (2005) and Sirmon et al. (2011) have yet to clearly explained. Further we observed in our case study research that there is a significant gap in delivered understanding about how complex, multilevels of AO management decision making should be decomposed, delivered and reintegrated into a coherent and effective whole. Such a gap in the delivery of holistic management decision making within firms needing a sustained ability to compete in dynamic markets had also been widely discussed within the general systems engineering literature.

In seeking to address these outstanding concerns, the present authors characterised and then used a simplification of emergent AO literature into a proposed 'reference model of AO processing'. Initially this model was formulated into a simple to use, visual interviewing tool for characterising and classifying procedural aspects of large scale change projects. This new reference model does not cover all aspects of AO in the organisations to maintain its ease of use. Never the less it was found to usefully structure and advise questioning during retrospective interviewing of mangers whom had contributed to the development and deployment of many collective decisions within a specific-case complex (project and organisational) decisional hierarchy; which had recently underpinned a major programme of change in a multi-national business. Further a direct outcome of the structured interviewing was a case study example of emergent $\mathrm{AO}$ thinking in action; which in itself usefully extends the base of emergent AO literature, by providing concrete examples of mappings between needed AO processes, wellstructured $\mathrm{AO}$ decisions and actions, leading to consequent asset transformations.

The simple visual reference model was also found during interviewing to usefully structure and document the positioning of multi-level descriptions of AO processes and resources descriptions that had to be realised as part of this particular transformational change project. Indeed, despite significant differences in their company position and parent discipline the reference model (and its embedded AO thinking) was rapidly understood by those managers interviewed and was accepted as a ready means of communicating change project ideas across role, disciplinary and organisational boundaries.

\subsection{Conclusion}

In summary the proposed new 'systematic approach to AO application' was conceived and designed by the present authors to help 'underpin, visualise and integrate' critical aspects of specific case change projects needed within firms to 'sustain competitive behaviours within uncertain environments'. The approach is systematic but simplistic. It does not itself direct specific decision making; it only describes the primary decision making phases that should be actioned and example uses of underpinning cognitive maps which must have shared ownership and essentially invoke common understandings by the various members of transient teams of people who will action phases of the change project. 
Further research includes mapping the AO processes used in the case study company to the reference model to demonstrate how the reference model with case information and cognitive models could direct the senior management teams' thinking as they formulate and evaluate alternative strategic futures.

\section{ACKNOWLEDGEMENTS}

Sincere thanks are offered to: Professor Paul Foley, MD of Tech4i2 Ltd, UK for his practical insights into Asset Orchestration and Universiti Teknikal Malaysia Melaka, University of Leicester and University of Al- Fallujah for funding this study.

\section{References}

1. Porter ME., What is strategy?. Harvard Business Review. 74(6), 61-78 (1996).

2. Efthymiou, K., Pagoropoulos, A., Papakostas, N., Mourtzis, D. and Chryssolouris, G. Manufacturing systems complexity: An assessment of manufacturing performance indicators unpredictability. CIRP Journal of Manufacturing Science and Technology. 7(4), 324-334 (2014).

3. Eisenhardt, K.M. and Martin, J.A. Dynamic capabilities: what are they?. Strategic management journal. 21(10-11), 1105-1121 (2000).

4. Barney, J.B. Firm resources and sustained competitive advantage. Journal of Management. 17(1), 99-120 (1991).

5a,b. $\quad$ Adner, R. and Helfat, C.E. Corporate effects and dynamic managerial capabilities. Strategic Management Journal. 24(10), 1011-1025 (2003).

6. Sirmon, D.G. and Hitt, M.A. Contingencies within dynamic managerial capabilities:interdependent effects of resource investment and deployment on firm performance, Strategic Management Journal. 30(13), 1375-1394 (2009).

7. Sirmon, D.G. and Hitt, M.A. Managing resources: Linking unique resources, management, and wealth creation in family firms. Entrepreneurship theory and practice. 27(4), 339-358 (2003).

8a,b,c. $\quad$ Sirmon, D.G., Hitt, M.A., Ireland, R.D. and Gilbert, B.A. Resource orchestration to create competitive advantage: breadth, depth, and life cycle effects. Journal of Management. 37(5), 1390-1412 (2011).

9. Helfat, C.E., Finkelstein, S., Mitchell, W., Peteraf, M., Singh, H., Teece, D. and Winter, S.G. Dynamic Capabilities: Understanding Strategic Change in Organizations, MA: John Wiley \& Sons (2007).

10a,b. Teece, D.J. Dynamic capabilities: Routines versus entrepreneurial action. Journal of management studies, 49(8), 1395-1401 (2012).

11a,b. Taylor, A. and Helfat, C.E. Organizational linkages for surviving technological change: complementary assets, middle management, and ambidexterity. Organization Science, 20(6), 718-739 (2009).

12. Chadwick, C., Super, J.F. and Kwon, K. Resource orchestration in practice: CEO emphasis on SHRM, commitment-based HR systems, and firm performance", Strategic Management Journal, 36(3), 360-376 (2015). 